\title{
Oral administration of curcumin (Curcuma longa) can attenuate the neutrophil inflammatory response in zymosan-induced arthritis in rats ${ }^{1}$
}

\author{
Nilson Nonose ${ }^{\mathrm{I}}$, José Aires Pereira ${ }^{\mathrm{II}}$, Paulo Roberto Moura Machado ${ }^{\mathrm{III}}$, Murilo Rocha Rodrigues ${ }^{\mathrm{IV}}$, Daniela Tiemi Sato ${ }^{\mathrm{IV}}$, Carlos \\ Augusto Real Martinez ${ }^{\mathrm{V}}$ \\ DOI: http://dx.doi.org/10.1590/S0102-86502014001800006 \\ IFellow Master degree, Postgraduate Program in Health Sciences, Sao Francisco University (USF), Bragança Paulista-SP, Brazil. Technical procedures, \\ acquisition and interpretation of data, manuscript preparation. \\ IIAssistant Professor, Department of Pathology, USF, Bragança Paulista-SP, Brazil. Histopathological examinations and histological analysis. \\ IIIPhD, Assistant Professor, Department of Orthopedics, Sao Francisco University Medical Hospital (HUSF), Bragança Paulista-SP, Brazil. Technical \\ procedures, acquisition of data, critical revision. \\ ${ }^{\text {IV }}$ Graduate student, USF, Bragança Paulista-SP, Brazil. Scientific initiation student, Grant from Institutional Program for Scientific Initiation (PIBIC) \\ of the National Council of Technological and Scientific Development (CNPq), Ministry of Science, Technology and Innovation, Brazil. Technical \\ procedures, acquisition of data. \\ vAssociate Professor, Postgraduate Program in Health Sciences, USF, Bragança Paulista-SP. Associate Professor, Campinas State University \\ (UNICAMP), Brazil. Conception and design of the study, manuscript writing, supervised all phases of the study, critical revision.
}

\section{ABSTRACT}

PURPOSE: To evaluate the effect of curcumin in the acute phase of zymosan-induced arthritis.

METHODS: Twenty-eight male rats were subjected to intra-articular infiltration of zymosan of both knees and, in four the infiltration was made with saline. The animals were divided into five groups second received every six hours by gavage: corn oil by (positive and negative control); curcumin (100 mg/kg); prednisone $1 \mathrm{mg} / \mathrm{kg} / \mathrm{day}$; prednisone $8 \mathrm{mg} / \mathrm{kg}$. All animals were sacrificed after six, $12,24 \mathrm{and}$ 48 hours of the infiltration. The knees were removed for evaluation of neutrophil infiltration. The number of neutrophils was counted by computer-assisted analysis of the images. The neutrophil infiltrate was stratified into four grades: $0=$ normal; $+=$ mild; $++/+++=$ moderate; $>++++=$ severe. The results were compared using the Mann-Whitney test and the variance by Kruskal-Wallis test adopting a significance level of $5 \%(\mathrm{p}<0.05)$.

RESULTS: Curcumin reduces inflammatory activity in the first six hours after zymosan-induced arthritis when compared to saline $(\mathrm{p}<0.01)$. This was also observed in animals subjected to administration of prednisone $(1 \mathrm{mg} / \mathrm{kg})$ and those treated with prednisone $(8$ $\mathrm{mg} / \mathrm{kg}$ ). Curcumin was more effective than lower doses of prednisone in the first six hours after induction of the arthritis. After 12,24 and 48 hours, curcumin does not have the same anti-inflammatory effects when compared to prednisone. After 48 hours, prednisone is more effective than curcumin in reducing the inflammatory infiltrate regardless of the dose of prednisone used.

CONCLUSION: Oral administration of curcumin reduces inflammation in the first six hours after experimentally zymosan-induced arthritis. Key words: Arthritis, Experimental. Zymosan. Curcumin. Prednisone. Neutrophil Infiltration. Numerical Analysis, Computer-Assisted. Rats. 


\section{Introduction}

Arthritis is a degenerative joint disease with a high prevalence and is a major cause of disability worldwide ${ }^{1}$. The continuous inflammatory process leads to progressive destruction of the cartilage, bone changes and chronic inflammation of the synovial membranes. The intense and continuous pain in the involved joints limits movements and results in the patient becoming depressed and isolated from his/her social life ${ }^{2,3}$. In addition to interfering with the quality of life, arthritis has a substantial impact on treatment and medical care costs ${ }^{4}$.

Arthritis can affect any joint. However, in descending order, the knees are the most commonly affected joints, followed by the hips, hands, spine, wrists and ankles ${ }^{3}$. It is estimated that $35 \%$ of individuals over 30 years of age already show clinical and radiological signs of arthritis in the knees and that $85 \%$ of patients over 70 years of age have radiographic changes in their knee joints that allow the diagnosis of disease ${ }^{1,3}$. Although the etiology of arthritis is still uncertain, some risk factors have been related to its pathogenesis, including age, endocrine and metabolic disorders, ethnic, genetic and mechanical trauma ${ }^{1}$.

Symptoms in patients with arthritis are related to joint wear, synovitis of repetition, degeneration of ligaments, joint capsule changes, osteoporosis, presence of joint effusion, and most likely the formation of crystal deposits (apatite) in the synovial membrane. Pain is the primary and dominant symptom in patients with arthritis of any kind. It features variable intensity according to the phase of the disease and may be cyclic or constant, and it is worse with joint movement and improves with rest. In mild forms, the pain appears only after application of pressure on the involved joint, and it improves with rest and analgesics or nonsteroidal anti-inflammatory drugs (NSAIDs). With the progression of the frame, pain becomes more intense, with patients requiring higher doses of anti-inflammatory medications and having shorter pain-free intervals. In severe forms, pain arises even at rest, which makes any attempt of motion impossible; therefore, the patient needs to use stronger analgesics, including opioids and glucocorticoids (GC). Patients are frequently also treated with GC by mouth or by joint infiltration as well as with immunosuppressive drugs and more recently monoclonal anti-TNF- $\alpha$. With the progressive degeneration of articular cartilage, inflammation by continuous stiffness is of variable length, resulting in limitation of motion and crepitus of the joint during flexion and extension.

Studies in experimental models of arthritis have shown that neutrophils are the first cells to migrate into the joint ${ }^{5}$.
The activated neutrophils promote phagocytosis of immune complexes formed in the early stages, releasing reactive oxygen species (ROS) and thus leading to an oxidative stress on the articular cartilage and eicosanoids that increase the production of proinflammatory cytokines ${ }^{5}$. The inflammatory response causes an increase in blood flow and local transudation of histamine and serotonin, thereby increasing the neutrophil infiltration, with consequent overproduction of ROS. Studies have shown that in the pathogenesis of arthritis, damage to the cartilage is related to oxidative stress caused by the excessive formation of ROS, as well as by blocking or reducing the signaling pathways of antioxidant systems ${ }^{6,7}$.

To relieve limiting painful symptoms, most patients use anti-inflammatory and analgesic medications in a continuous manner. For ease of acquisition and the concomitant analgesic, anti-inflammatory hormonal and non-steroidal drugs are commonly consumed. Chronic use of these substances, often without medical supervision, at a high dosage for long periods results in serious adverse effects on the digestive, renal, cardiac and hematologic systems. Finding natural substances with potential antioxidant effects that also have anti-inflammatory and analgesic effects and low rates of side effects is an old aspiration. New substances are constantly being tested, showing activity against arthritis both in vitro and in vivo.

A natural substance that has shown amazing effects for the treatment of osteoarthritis is curcumin, the active ingredient extracted from the root of Curcuma longa (Indian curry), which was already used by Ayurvedic medicine ${ }^{8}$. Among the many potential uses of the curcumin, its intense antioxidant activity stands out ${ }^{9,10}$. When considering that there is a significant formation of ROS by the synovium in patients with arthritis, it is possible that curcumin will be useful in treating this disease ${ }^{11}$. It is possible that the antioxidant effects of curcumin can minimize oxidative damage to the articular cartilage and improve the symptoms of the disease. However, to the best of our knowledge, the anti-inflammatory effects of curcumin have not been tested in experimental models of zymosan-induced arthritis ${ }^{12-14}$. Thus, the aim of this study was to determine whether oral administration of curcumin enhances the acute inflammatory response in experimental arthritis.

\section{Methods}

This study was approved in accordance with Federal Law No. 11.794 (10/08/2008) and the Ethics Committee in Animal Research of Sao Francisco University receiving the certificate No. 003.06.11 (09/22/2011). 
Forty male SPF Wistar rats (300-350g) were obtained from the central vivarium of the Sao Francisco University School of Medicine. The rats were maintained under 12-hour light/dark cycles and fed a standard rodent chow diet. The animals were deprived of food, but not water, for 12 hours prior to the surgical procedure.

\section{Arthritis induction}

The experiment was started at 6 o'clock in the morning. The animals were initially weighed, and the induction of arthritis was always performed under general anesthesia by intraperitoneal administration of $0.1 \mathrm{ml} / 100 \mathrm{~g}$ of a $1: 1(\mathrm{v} / \mathrm{v})$ solution of ketamine $(50 \mathrm{mg} / \mathrm{ml})$ and xylazine $(20 \mathrm{mg} / \mathrm{ml})$. The induction of the arthritis was performed on 24 animals of the experimental group and four of the positive control group by infiltration of $0.05 \mathrm{~mL}$ zymosan (1 $\mathrm{mg} / 50 \mu \mathrm{L}$ ) in both knee joints using disposable insulin syringes. Four animals of the negative control group received the same intra-articular volume of saline.

\section{Experimental groups}

The animals were divided into the following five groups: A) Positive control: after the induction of arthritis, the animals received gastric gavage with corn oil every six hours for 48 hours $(n=4)$; B) Negative control: the rats received intra-articular infiltration with saline in both knees and gastric gavage with corn oil every six hours for 48 hours ( $n=4)$; C) Curcumin: after the induction of arthritis, the animals received gastric gavage every six hours for 48 hours with curcumin (Sigma-Aldrich Ltd., USA) at dose $100 \mathrm{mg} / \mathrm{kg}(\mathrm{n}=8)$; D) after the induction of arthritis, the rats received gastric gavage every six hours for 48 hours with prednisone at dose of $1 \mathrm{mg} / \mathrm{kg} / \mathrm{day}$ $(n=8)$; E) after the induction of the arthritis, the animals received gastric gavage every six hours for 48 hours with prednisone at dose of $8 \mathrm{mg} / \mathrm{kg} /$ day $(\mathrm{n}=8)$. The animals in all experimental groups were sacrificed after six, 12, 24 and 48 hours.

After sacrifice, tissue samples containing the cartilage and synovial of both knees were removed. Fragments prepared for histological analysis were immersed in 10\% neutral buffered formalin (Sigma, St. Louis, MO, USA) for $24 \mathrm{~h}$, dehydrated in increasing ethanol concentrations, and embedded in paraffin. Thereafter, 5- $\mu \mathrm{m}$ sections of tissue were cut using a rotary microtome (Leica Biosystems, Nussloch, Germany), mounted on glass slides, cleared, hydrated and stained with hematoxylin-eosin (HE) for histological evaluation. Slide analysis was performed by a pathologist experienced in arthritis who was unaware of the source material and the objectives of the study using an optical microscope (Eclipse DS-50, Nikon Inc., Osaka, Japan). Photomicrographs were taken with a digital video-capture camera (DS-Fi-50; Nikon Inc., Osaka, Japan) coupled to the microscope body. The number of neutrophils per field was measured by computer-assisted image analysis system (NIS-Elements; Nikon Inc., Osaka, Japan), evaluating the image of three random fields in each histological slide. The final value adopted for each slide was represented by the median of the values found in the evaluation of the three selected fields.

The intensity of the inflammatory infiltrate was graded in crosses (from - to $6+$ ) according to the number of neutrophils founded in each histological fields. The final value adopted for each animal was the average found after analysis of three distinct histological fields and represents the inflammatory grade. According to the points obtained in the inflammatory grade, graduation was stratified as absent (0), mild (1 and 2), moderate ( 3 and 4 ) and severe (5 and 6), to what is called the degree of inflammation (Table 1).

TABLE 1 - Grading scale of degree of the inflammation.

\begin{tabular}{lcc}
\hline Degree of inflammation & Score & Histological characteristics \\
\hline Absent & 0 & normal \\
Mild & $1-2$ & Mild intensity \\
Moderate & $3-4$ & Moderate intensity \\
Severe & $5-6$ & Severe intensity \\
\hline
\end{tabular}

The statistical analysis of the obtained results was performed using a significance level of $5 \%(\mathrm{p}<0.05)$. The data obtained from the analyzed colon segment in each experimental group were expressed as the mean values and the respective standard error using SPSS statistical software version 13.0 (SPSS Inc., Chicago, USA) for Windows. Significant results are marked with a simple asterisk when $\mathrm{p}<0.05$ and with a double asterisk when $\mathrm{p}<0.01$. The Mann-Whitney test was used to compare inflammation scores between the control and experimental animal groups. The Kruskal-Wallis test was used to analyze the variance in the degree of inflammation between the different groups.

\section{Results}

Figure 1A shows the synovial membrane and articular cartilage removed from a normal animal's knee in the negative control group (not subjected to infiltration with zymosan). Figure 1B shows the articular cartilage and the synovia of a knee removed from an animal in the control positive group after six hours of gastric gavage with corn oil. 


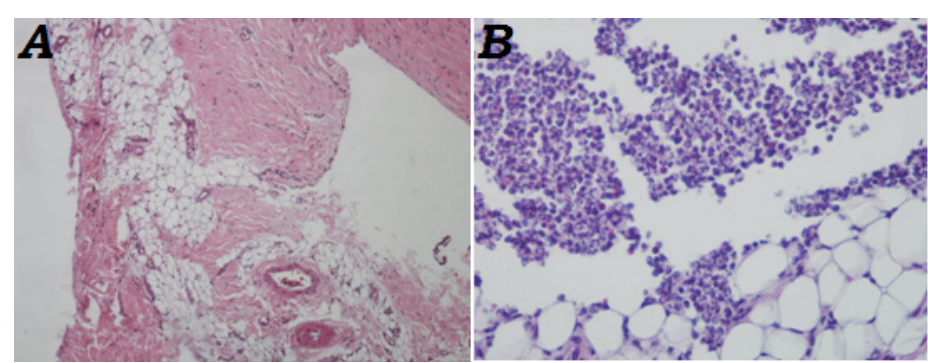

FIGURE 1 - A: Synovial membrane and articular cartilage from animal's knee after six hours of negative control group showing without neutrophil infiltration (HE x100). B: Synovial membrane and articular cartilage from animal's knee after six hours of positive control group showing severe neutrophil infiltrate (HE x100).

Figure $2 \mathrm{~A}$ shows the articular cartilage and synovial membrane removed from an animal in the experimental group subjected to gastric gavage with curcumin $(100 \mathrm{mg} / \mathrm{kg})$ after six hours of articular-induced arthritis with zymosan. Figure 2B shows the articular cartilage and synovial membrane removed from an animal in the experimental group subjected to gastric gavage with curcumin $(100 \mathrm{mg} / \mathrm{kg})$ after 48 hours of articular-induced arthritis with zymosan.

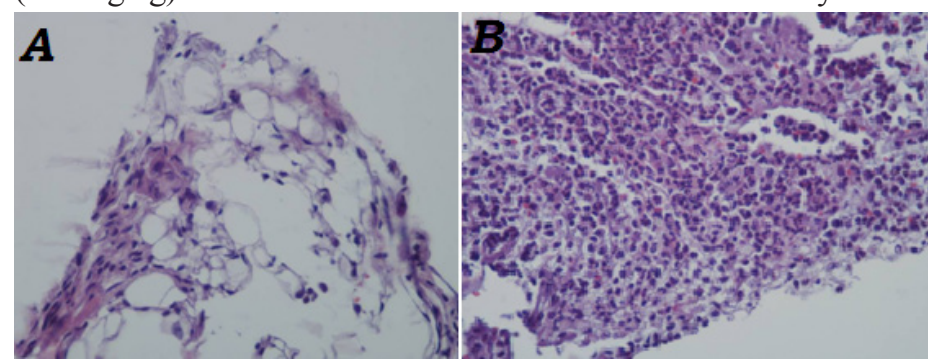

FIGURE 2 - A: Synovial membrane and articular cartilage from animal's knee after six hours of curcumin $(100 \mathrm{mg} / \mathrm{kg})$ oral gavage showing mild neutrophil infiltration (HE x100). B: Synovial membrane and articular cartilage from animal's knee after 48 hours of curcumin $(100 \mathrm{mg} / \mathrm{kg})$ oral gavage showing severe neutrophil infiltration (HE x100).

Figures 3A shows the articular cartilage and synovial membrane removed from an animal in the experimental group subjected to gastric gavage with prednisone $(1 \mathrm{mg} / \mathrm{kg})$ after six hours of induction of arthritis with zymosan. Figures 3B shows the articular cartilage and synovial membrane removed from an animal in the experimental group subjected to gastric gavage with prednisone (1 mg/ $\mathrm{kg}$ ) after 48 hours of articular-induced arthritis with zymosan.

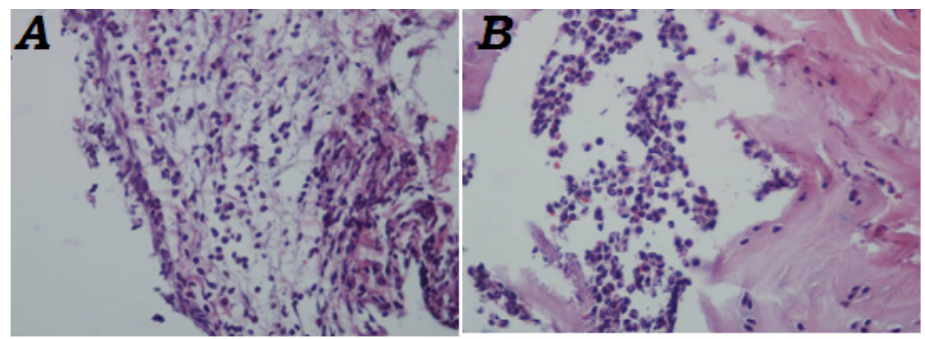

FIGURE 3 - A: Synovial membrane and articular cartilage from animal's knee after six hours of prednisone $(1 \mathrm{mg} / \mathrm{kg})$ oral gavage showing moderate neutrophil infiltration (HE x100). B: Synovial membrane and articular cartilage from animal's knee after 48 hours of prednisone $(1 \mathrm{mg} / \mathrm{kg})$ oral gavage showing moderate neutrophil infiltration (HE x100).
Figure 4A shows the articular cartilage and synovial membrane removed from an animal in the experimental group subjected to gastric gavage with prednisone $(8 \mathrm{mg} / \mathrm{kg})$ after six hours of induction of arthritis with zymosan. Figure 4B shows the articular cartilage and synovial membrane removed from an animal in the experimental group subjected to gastric gavage with prednisone ( 8 $\mathrm{mg} / \mathrm{kg}$ ) after 48 hours of articular-induced arthritis with zymosan.

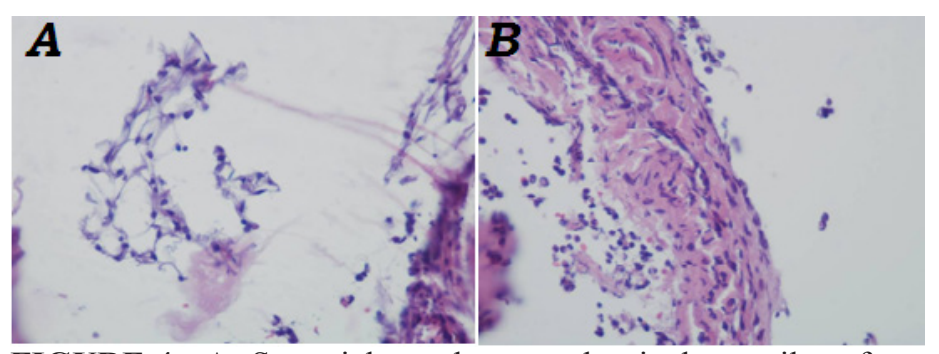

FIGURE 4 - A: Synovial membrane and articular cartilage from animal's knee after six hours of prednisone $(8 \mathrm{mg} / \mathrm{kg})$ oral gavage showing mild neutrophil infiltration (HE x100). B: Synovial membrane and articular cartilage from animal's knee after 48 hours of curcumin $(100 \mathrm{mg} / \mathrm{kg})$ oral gavage showing moderate neutrophil infiltration (HE x100).

Table 2 shows the mean values with their respective standard errors and the inflammatory scores at six, 12, 24 and 48 hours after gavage with corn oil, curcumin $(100 \mathrm{mg} / \mathrm{kg})$, and the different concentrations of prednisone $(1 \mathrm{mg} / \mathrm{kg}, 8 \mathrm{mg} / \mathrm{kg})$.

TABLE 2 - Degree of inflammation score after intervention with corn oil, curcumin, prednisone $(1 \mathrm{mg} / \mathrm{kg})$ and prednisone $(8 \mathrm{mg} / \mathrm{kg})$ in the knee arthritis induced by zymosan.

\begin{tabular}{|c|c|c|c|c|}
\hline & \multicolumn{4}{|c|}{ Mean \pm Standard Error } \\
\hline Hours & Corn oil & Curcumin & $\begin{array}{c}\text { Prednisone } \\
\text { (1 mg/kg) }\end{array}$ & $\begin{array}{c}\text { Prednisone } \\
(8 \mathrm{mg} / \mathrm{kg})\end{array}$ \\
\hline 6 & $5.75 \pm 0.25$ & $2.33 \pm 0.42 * * \dagger$ & $4.33 \pm 0.42 *$ & $2.16 \pm 0.16^{\dagger \dagger}$ \\
\hline 12 & $5.75 \pm 0.25$ & $5.75 \pm 0.25$ & $4.00 \pm 1.20$ & $4.75 \pm 0.47$ \\
\hline 24 & $5.75 \pm 0.25$ & $5.75 \pm 0.25$ & $5.50 \pm 0.28$ & $5.50 \pm 0.28$ \\
\hline 48 & $5.75 \pm 0.25$ & $5.75 \pm 0.25$ & $3.50 \pm 1.40$ & $3.50 \pm 1.40$ \\
\hline
\end{tabular}

$\mathrm{mg} / \mathrm{kg}$, milligrams/kilograms. $*=\mathrm{p}<0.05$ (control $\times$ prednisone $1 \mathrm{mg} / \mathrm{kg}$ ); $* *=$ $\mathrm{p}<0.01$ (control $\times$ curcumin and control $\times$ prednisone $8 \mathrm{mg} / \mathrm{kg}$ ) ${ }^{\dagger}=\mathrm{p}<0.05$ (curcumin $\times$ prednisone $1 \mathrm{mg} / \mathrm{kg}$ ); ${ }^{\dagger \dagger}=\mathrm{p}<0.01$ (prednisone $1 \mathrm{mg} / \mathrm{kg} \times$ prednisone 8 $\mathrm{mg} / \mathrm{kg}$ ). Mann-Whitney test.

Table 3 shows the variations in the inflammatory scores in animals of the positive control and experimental groups subjected to gastric gavage with corn oil, curcumin $(100 \mathrm{mg} / \mathrm{kg})$, and different concentrations of prednisone $(1 \mathrm{mg} / \mathrm{kg}, 8 \mathrm{mg} / \mathrm{kg})$ at different time points during the experiment. 
TABLE 3 - Degree of inflammation score after intervention with corn oil, curcumin, and different concentrations of prednisone $(1 \mathrm{mg} / \mathrm{kg}, 8 \mathrm{mg} / \mathrm{kg})$ in knee arthritis induced by zymosan.

\begin{tabular}{lcccc}
\hline \multicolumn{5}{c}{ Hours } \\
\hline Hours & $\mathbf{6}$ & $\mathbf{1 2}$ & $\mathbf{2 4}$ & $\mathbf{4 8}$ \\
\hline Corn oil & $5.75 \pm 0.25$ & $5.75 \pm 0.25$ & $5.75 \pm 0.25$ & $5.75 \pm 0.25$ \\
Curcumin & $2.33 \pm 0.42 * *$ & $5.25 \pm 0.25$ & $5.75 \pm 0.25$ & $5.75 \pm 0.25$ \\
$\begin{array}{l}\text { Prednisone } \\
(\mathbf{1} \mathbf{~ m g} / \mathbf{k g} / \text { day) }\end{array}$ & $4.33 \pm 0.42$ & $4.00 \pm 1.20$ & $5.50 \pm 0.28$ & $3.50 \pm 1.40 *$ \\
$\begin{array}{l}\text { Prednisone } \\
\mathbf{( 8 ~} \mathbf{~ m g / k g / d a y ) ~}\end{array}$ & $2.16 \pm 0.16^{* *}$ & $4.75 \pm 0.47$ & $5.50 \pm 0.28$ & $3.50 \pm 1.40$ \\
\hline
\end{tabular}

$\mathrm{mg} / \mathrm{kg}$, milligrams/kilograms. Kruskal-Wallis test. * $=\mathrm{p}<0.05(48$ hours $\times 6,12$ and 24 hours); $* *=\mathrm{p}<0.01$ ( 6 hours $\times 12,24$ and 48 hours).

\section{Discussion}

The main objective of the treatment of different forms of arthritis is to reduce inflammation within the joints ${ }^{15}$. There are several drugs that meet that goal, and among them, substances that interrupt the inflammatory cascade deserve a prominent place. For decades, the use of substances with anti-inflammatory action has been the main treatment option. The anti-inflammatory medications can be divided into the following two major groups: steroids and non-steroids substances.

Different types of GC mainly represent the steroids class. GC are hormones produced and secreted by the cortical region of the adrenal glands and are involved in various physiological functions and adaptation to stress ${ }^{15}$. Cortisol or hydrocortisone is the main circulating GC produced by humans, and its synthesis is regulated by the pituitary hormone adrenocorticotropic hormone $(\mathrm{ACTH})$, which is released in response to stimulation by a neuropeptide called corticotrophin-releasing factor produced in the hypothalamus. Cortisol and its synthetic analogues are well absorbed from the gastrointestinal tract, and its intra-articular use is often performed by rheumatologists and orthopedists when other systemic actions of these drugs are unwanted. Continued use of $\mathrm{GC}$ is associated with various side effects, mainly represented by the development of peptic ulcers associated with gastrointestinal bleeding, congestive heart failure, cardiac edema in the lower limbs, osteoporosis, immune suppression and Cushing's syndrome.

Anti-inflammatory non-steroidal (AINS) medications are substances that block cyclooxygenase, thereby preventing the synthesis of eicosanoids by the metabolic pathway of the arachidonic acid cascade ${ }^{15}$. Despite being universally effective and used in the form of mild and moderate arthritis, the use of AINS is limited due to the high incidence of side effects such as digestive disorders (acute gastric mucosal lesions, gastrointestinal bleeding and peptic ulcer), severe anaphylactic reactions, kidney failure, abnormal platelet aggregation, bleeding diathesis and myocardial infarction.

With the aim of finding natural substances that exhibit anti-inflammatory activity in the treatment of arthritis and that exhibit minimal side effects, the efficacies of a number of natural substances are being increasingly tested in experimental models of $\operatorname{arthritis}^{16,17}$. Among these substances, curcumin, derived from the root of the plant Curcuma longa, which is rich in diferuloylmethane, has been one of the most promising natural active ingredients ${ }^{17-19}$. Its use for the treatment of various inflammatory diseases, including arthritis, has already been described for thousands of years by Ayurvedic medicine and traditional Chinese medicine ${ }^{11}$. The active ingredient was identified more than two centuries $\mathrm{ago}^{20}$. Curcumin has a potent immunomodulatory effect on the inflammatory response and may regulate the activation of $\mathrm{T}$ lymphocytes, B-lymphocytes, macrophages, neutrophils and dendritic cells. Recent studies have demonstrated that curcumin can also decrease the tissue expression of various proinflammatory cytokines, including TNF- $\alpha$. IL-1, IL-2, IL-6, IL12 , and inactivating transcription factor NF-kB and, at low doses, stimulate antibody production ${ }^{21-23}$. These effects appear to confirm the potential of curcumin for the treatment of arthritis in human and experimental models of induced-arthritis ${ }^{24-26}$.

Several experimental animal models have investigated the anti-inflammatory effects of curcumin. Initial studies evaluating its effect on carrageenan-induced edema in the fat pads of rats' paws confirmed that doses between 50 and $200 \mathrm{mg} /$ $\mathrm{kg}$ were able to reduce tissue swelling. Experimental models in mice showed that $50 \%$ curcumin reduces local edema at a dose of $48 \mathrm{mg} / \mathrm{kg}$, and a similar effect is observed with similar doses of cortisone and phenylbutazone. In addition, doses of 20-80 $\mathrm{mg} / \mathrm{kg}$ reduced edema and inflammatory infiltrate in rats. The administration of curcumin also inhibits formaldehyde-induced arthritis in rats at a dose of $40 \mathrm{mg} / \mathrm{kg}$, and this dose has negligible levels on peptic ulcer formation compared to phenylbutazone, and without any acute toxicity at doses of up to $2 \mathrm{~g} / \mathrm{kg}^{27}$. A doubleblind, randomized controlled trial compared the administration of curcumin with phenylbutazone. After administration of $1.200 \mathrm{mg} /$ day of curcumin, the authors found improvement in joint swelling, morning stiffness and increased length of ambulation in patients with severe rheumatoid arthritis ${ }^{28}$. However, few studies have evaluated the effects of curcumin on acute inflammatory changes

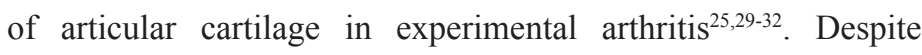
curcumin being used for centuries in Indian medicine as an antiinflammatory substance, evaluation of its therapeutic effects in 
experimental arthritis has been limited ${ }^{33}$. No studies have evaluated the effects of curcumin in an experimental arthritis model induced by zymosan or compared the effects of substance with prednisone, which makes this a pioneer study.

Some studies have evaluated the effects of curcumin alone or combination with other medications with anti-inflammatory effects. Taty Anna et al. ${ }^{19}$, evaluated increasing doses of curcumin (30, 60 and $110 \mathrm{mg} / \mathrm{mL} / \mathrm{kg}$ ) associated with GC (betamethasone at a dose of $0.5 \mathrm{mg} / \mathrm{mL} / \mathrm{kg}$ ) applied orally daily for four weeks in an experimental model of collagen-induced arthritis. They showed that there was significant improvement in inflammatory score, radiographic score and erythrocyte sedimentation rate in animals treated with the higher doses. However, the main criticism is that the study cannot evaluate if the effect is due to curcumin alone or, more likely, the synergism between the two substances. Ramadan et al. ${ }^{22}$, compared the anti-inflammatory and antioxidant roots of curcumin and ginger, both at a dose of $200 \mathrm{mg} / \mathrm{kg}$, in an experimental model of adjuvant-induced arthritis. They found that both rhizomes were able to reduce the incidence and severity of arthritis by increasing and decreasing proinflammatory and anti-inflammatory cytokines, respectively, and activating the antioxidant defense systems. When compared to curcumin extract of ginger and indomethacin, they found that curcumin showed an anti-arthritic effect that was superior that of other substances, particularly when administered from the day of the induction of arthritis. They concluded that the results proved that the anti-inflammatory and antioxidant effects of curcumin are stronger than those of ginger and indomethacin. Its low cost and lack of adverse effects make the substance potentially effective in treating arthritis ${ }^{22}$. Phase 1 studies have shown that even high doses of curcumin (12 g/day), although safe, present with low availability in serum ${ }^{16}$. Because the extract of Curcuma longa is not water soluble, we chose to dissolve it in corn oil. Other authors have chosen to dissolve the plant extract in olive oil ${ }^{19}$. Therefore, it is possible that the vehicle used has also interfered with the absorption. A previous study demonstrated that the use of pure oral powder of a commercialized extract containing $94 \%$ of the three main curcuminoids is more potent in preventing arthritis than essential oil substances ${ }^{31}$. It is possible that the administration of curcumin parenteral could provide higher availability; however, this type of administration diminishes the advantage of using the substance over other drug options for the treatment of arthritis. The use of nanoparticles or curcumin involved in phospholipid complexes, or the synthesis of analogous substances, appears to have solved the problems of low bioavailability because they favor the absorption and metabolism delay ${ }^{31}$.
In this this study when were counted the number of neutrophils per field in the control (positive and negative) and the experimental groups (curcumin, prednisone $1 \mathrm{mg} / \mathrm{kg}$ and $8 \mathrm{mg} / \mathrm{kg}$ ) six hours after the induction of arthritis by zymosan was found lower number of neutrophils per field in negative control group than the positive control group $(\mathrm{p}<0.01)$. When comparing animals subjected to gastric gavage with curcumin and prednisone $(1 \mathrm{mg} / \mathrm{kg})$ with the positive controls, we found a significant reduction in the numbers of neutrophils per field $(p<0.01)$. After 12 hours of the intervention with curcumin and the two doses of prednisone, we could not find a reduction in the number of neutrophils compared with the positive control group, but a significantly higher number was observed when compared with the negative control. After 48 hours of intervention, we confirmed that animals subjected to gastric gavage with $1 \mathrm{mg} /$ $\mathrm{kg}$ of prednisone had a lower number of neutrophils counted per field than the positive control group $(\mathrm{p}<0.01)$. After 48 hours, the intervention of both substances did not reduce the number of neutrophils when compared with the positive control group. In other words, the results of this study shown that curcumin has early anti-inflammatory activity. It's reduces the inflammation in the joint within the first six hours after the induction of arthritis, showing similar therapeutic efficacy even at doses comparable to steroids immunosuppressive doses and exceeding the anti-inflammatory effects observed with GC. However, after 12 and 24 hours, the anti-inflammatory effects of curcumin become similar to those of prednisone at both doses and do not alter the degree of inflammation. These findings may be related to low plasma and tissue levels of curcumin due to the low absorption by the digestive tract, and rapid systemic metabolism and elimination ${ }^{18}$. It is possible that the use of drugs by the parenteral route, dissolved in lipid vehicles capable of intravenous administration, can enhance the activity of the substance during that period.

The results of this study suggest that curcumin may be a useful drug for treating the acute phase of arthritis; however, additional studies have to be performed to improve the effectiveness of the substance. Research comparing increasing concentrations of the drug through different routes of administration, and especially improving their bioavailability, are still required to enable the use of curcumin.

\section{Conclusion}

Oral administration of curcumin may be a useful strategy for treating the initial phase of zymosan-induced arthritis. 


\section{References}

1. Lawrence RC, Felson DT, Helmick C G, Arnold LM, Choi H, Deyo RA, Gabriel S, Hirsch R, Hochberg MC, Hunder GG, Jordan JM, Katz JN, Kremers HM, Wolfe F. National Arthritis Data Workgroup. Estimates of the prevalence of arthritis and other rheumatic conditions in the United States. Part II. Arthritis Rheum. 2008 Jan;58(1):26-35. doi: 10.1002/art.23176.

2. Mahajan A, Verma S, Tandon V. Osteoarthritis. J Ass Physicians India. 2005 Jul;53:634-41. PMID: 16190135.

3. Arden N, Nevitt MC. Osteoarthritis: epidemiology. Best Pract Res Clin Rheumatol. 2006 Feb;20(1):3-25. PMID:16483904.

4. Dibonaventura M, Gupta S, McDonald M, Sadosky A. Evaluating the health and economic impact of osteoarthritis pain in the workforce: results from the National Health and Wellness Survey. BMC Musculoskelet Disord. 2011 Apr 28;12:83. doi: 10.1186/14712474-12-83.

5. Rocha FA, Andrade LE, Jancar S. Immune complex induced arthritis in rats: role of lipid mediators on cell infiltration. Med Inflam. 1996; 5(2):104-9. PMID: 18475706.

6. Henrotin YE, Bruckner P, Pujol JP. The role of reactive oxygen species in homeostasis and degradation of cartilage. Osteoarthritis Cartilage. 2003 Oct;11(10):747-55. PMID:13129694.

7. Fermor B, Christensen SE, Youn I, Cernanec JM, Davies CM, Weinberg JB. Oxygen, nitric oxide and articular cartilage. Eur Cell Mater. 2007 Apr 11;13:56-65; discussion 65. PMID: 17427142.

8. Jurenka JS. Anti-inflammatory properties of curcumin, a major constituent of Curcuma longa: A review of pre-clinical and clinical research. Altern Med Rev. 2009 Jun;14(2):141-53. PMID:19594223.

9. Chopra A, Lavin P, Patwardhan B, Chitre D. A 32-week randomized, placebo-controlled clinical evaluation of RA-11, an Ayurvedic drug, on osteoarthritis of the knees. Clin Rheumatol. 2004 Oct;10(5):23645. PMID: 17043520

10. Park C, Moon DO, Choi IW, Choi BT, Nam TJ, Rhu CH, Kwon TK, Lee WH, Kim GY, Choi YH. Curcumin induces apoptosis and inhibits prostaglandin $\mathrm{E}(2)$ production in synovial fibroblasts of patients with rheumatoid arthritis. Int J Mol Med. 2007 Sep;20(3):365-72. PMID: 17671742.

11. Funk JL, Oyarzo JN, Frye JB, Chen G, Lantz RC, Jolad SD, Sólyom AM, Timmermann BN. Turmeric extracts containing curcuminoids prevent experimental rheumatoid arthritis. J Nat Prod. 2006 Mar;69(3):351-5. PMID: 16562833.

12. Chaves HV, Ribeiro R de A, de Souza AM, Rodrigues e Silva AA, Gomes AS, Vale ML, Bezerra MM, Brito GA. Experimental model of zymosan-induced arthritis in the rat temporomandibular joint: role of nitric oxide and neutrophils J Biomed Biotechnol. 2011;2011:707985. doi: 10.1155/2011/707985.

13. Keystone EC, Schorlemmer HU, Pope C, Allison AC. Zymosaninduced arthritis: a model of chronic proliferative arthritis following activation of the alternative pathway of complement. Arthritis Rheum. 1977 Sep-Oct;20(7):1397-401. PMID: 911357.

14. Gegout P, Gillet P, Terlain B, Netter P. Zymosan induced arthritis in rats II. Effects of antiinflammatory drugs. Life Sci. 1995;56(20):PL389-94. PMID: 7723595.

15. Berner J, Gabay C. Best practice use of corticosteroids in rheumatoid arthritis. Rev Med Suisse. 2014 Mar 12;10(421):603-6, 608. PMID 24701713

16. Narendhirakannan RT, Limmy TP. Anti-inflammatory and antioxidant properties of Sida rhombifolia stems and roots in adjuvant induced arthritic rats. Immunopharmacol Immunotoxicol. 2012 Apr;34(2):326-36. doi: 10.3109/08923973.2011.605142.

17. Aggarwal BB, Sundaram C, Malani N, Ichikaw, H. Curcumin: the Indian solid gold. Adv Exp Med Biol. 2007;595:1-75. PMID:
17569205.

18. Anand P, Kunnumakkara AB, Newman RA, Aggarwal BB Bioavailability of curcumin: problems and promises. Mol Pharm. 2007 Nov-Dec;4(6):807-18. PMID: 17999464.

19. Taty Anna K, Elvy Suhana MR, Faizah O, Hamzaini AH. Antiinflammatory effect of Curcuma longa (turmeric) on collageninduced arthritis: an anatomico-radiological study. Clin Ter. 2011;162(3):201-7. PMID: 21717043.

20. Shishodia S, Sethi G, Aggarwal BB. Curcumin: getting back to the roots. Ann N Y Acad Sci. 2005 Nov;1056:206-17. PMID: 16387689.

21. Samuhasaneeto S, Thong-Ngam D, Kulaputana O, Suyasunanont D, Klaikeaw N. Curcumin decreased oxidative stress, inhibited NFkappaB activation, and improved liver pathology in ethanol-induced liver injury in rats. J Biomed Biotechnol. 2009;2009:981963. doi: $10.1155 / 2009 / 981963$.

22. Ramadan G, AL-Kahtani MA, EL-Sayed WM. Anti-inflammatory and anti-oxidant properties of Curcuma longa (turmeric) versus Zingiber officinale (ginger) rhizomes in rat adjuvant-induced arthritis. Inflammation. 2011 Aug;34(4):291-301. doi: 10.1007/ s10753-010-9278-0.

23. Park C, Moon DO, Choi IW, Choi BT, Nam TJ, Rhu CH, Kwon TK, Lee WH, Kim GY, Choi YH. Curcumin induces apoptosis and inhibits prostaglandin $\mathrm{E}(2)$ production in synovial fibroblasts of patients with rheumatoid arthritis. Int J Mol Med. 2007 Sep;20(3):365-72. PMID: 17671742.

24. Mun SH, Kim HS, Kim JW, Ko NY, Kim DOK, Lee BY, Kim B, Won HS, Shin HS, Han JW, Lee HY, Kim YM, Choi WS. Oral administration of curcumin suppresses production of matrix metalloproteinase (MMP)-1 and MMP-3 to ameliorate collageninduced arthritis: inhibition of the PKCdelta/JNK/c-Jun pathway. J Pharmacol Sci. 2009 Sep;111(1):13-21. PMID: 19763044.

25. Moon DO, Kim MO, Choi YH, Park YM, Kim GY. Curcumin attenuates inflammatory response in IL-1beta-induced human synovial fibroblasts and collagen-induced arthritis in mouse model. Int Immunopharmacol. 2010 May;10(5):605-10. doi: 10.1016/j. intimp.2010.02.011.

26. Lantz RC, Chen GJ, Solyom AM, Jolad SD, Timmermann BN. The effect of turmeric extracts on inflammatory mediator production. Phytomedicine. 2005 Jun;12(6-7):445-52. PMID: 16008121.

27. Srimal RC, Dhawan BN. Pharmacology of diferuloyl methane (curcumin), a non-steroidal antiinflammatory agent. J Pharm Pharmacol. 1973 Jun;25(6):447-52. PMID: 4146582.

28. Baker CL Jr, Ferguson CM. Future treatment of osteoarthritis. Orthopedics. 2005 Feb;28(2 Suppl):s227-34. PMID: 15747611.

29. Banerjee M, Tripathi LM, Srivastava VM, Puri A, Shukla R. Modulation of inflammatory mediators by ibuprofen and curcumin treatment during chronic inflammation in rat. Immunopharmacol Immunotoxicol. 2003 May;25(2):213-24. PMID: 12784914.

30. Banji D, Pinnapureddy J, Banji OJ, Saidulu A, Hayath MS. Synergistic activity of curcumin with methotrexate in ameliorating Freund's Complete Adjuvant induced arthritis with reduced hepatotoxicity in experimental animals. Eur J Pharmacol. 2011 Oct 1;668(1-2):293-8. doi: 10.1016/j.ejphar.2011.06.006.

31. Funk JL, Frye JB, Oyarzo JN, Kuscuoglu N, Wilson J, McCaffrey G, Stafford G, Chen G, Lantz RC, Jolad SD, Sólyom AM, Kiela PR, Timmermann BN. Efficacy and mechanism of action of turmeric supplements in the treatment of experimental arthritis. Arthritis Rheum. 2006 Nov;54(11):3452-64. PMID: 17075840.

32. Jancinová V, Perecko T, Nosál R, Kostálová D, Bauerová K, Drábiková K. Decreased activity of neutrophils in the presence of diferuloylmethane (curcumin) involves protein kinase $\mathrm{C}$ inhibition. Eur J Pharmacol, 2009 Jun 10;612(1-3):161-6. doi: 10.1016/j. ejphar.2009.03.080. 
Nonose $\mathrm{N}$ et al.

33. Joe B, Rao UJ, Lokesh BR. Presence of an acidic glycoprotein in the serum of arthritic rats: modulation by capsaicin and curcumin. Mol Cell Biochem. 1997 Apr;169(1-2):125-34. PMID: 9089639.

\section{Correspondence:}

Prof. Carlos Augusto Real Martinez

Rua Rui Barbosa, 255/32

09190-370 Santo André - SP Brasil

Tel.: (55-11)4438-9203

Fax: (55-11)2199-8200

carmartinez@uol.com.br

Received: June 19, 2014

Review: Aug 18, 2014

Accepted: Sep 22, 2014

Conflict of interest: none

Financial source: Sao Paulo Research Foundation (FAPESP). Process N ${ }^{\circ}$ 2010/12492-7

${ }^{1}$ Research performed at Postgraduate Program in Health Sciences, Sao Francisco University (USF), Bragança Paulista-SP, Brazil. Part of Master degree thesis, Postgraduate Program in Health Sciences, USF. Tutor: Carlos Augusto Real Martinez. 